\title{
Comparative Genomics Revealing Insights into Niche Separation of the Genus Methylophilus
}

\author{
Nana Lin ${ }^{1,2}$, Ye Tao ${ }^{2,3}$, Peixin Gao ${ }^{2}$, Yan $X u^{1}$ and Peng Xing ${ }^{2, *(D)}$ \\ 1 School of Civil Engineering, Southeast University, Nanjing 210096, China; 220191214@seu.edu.cn (N.L.); \\ xuxucalmm@seu.edu.cn (Y.X.) \\ 2 State Key Laboratory of Lake Science and Environment, Nanjing Institute of Geography and Limnology, \\ Chinese Academy of Sciences, Nanjing 210008, China; taoye@biozeron.com (Y.T.); gao_px@sina.com (P.G.) \\ 3 College of Resources and Environment, University of Chinese Academy of Sciences, Beijing 100049, China \\ * Correspondence: pxing@niglas.ac.cn; Tel.: +86-25-8688-2112; Fax: +86-25-5771-4759
}

Citation: Lin, N.; Tao, Y.; Gao, P.; Xu, Y.; Xing, P. Comparative Genomics Revealing Insights into Niche Separation of the Genus Methylophilus. Microorganisms 2021, 9, 1577. https://doi.org/10.3390/ microorganisms 9081577

Academic Editor:

Nils Risgaard-Petersen

Received: 21 May 2021

Accepted: 22 July 2021

Published: 24 July 2021

Publisher's Note: MDPI stays neutral with regard to jurisdictional claims in published maps and institutional affiliations.

Copyright: (c) 2021 by the authors. Licensee MDPI, Basel, Switzerland. This article is an open access article distributed under the terms and conditions of the Creative Commons Attribution (CC BY) license (https:/ / creativecommons.org/licenses/by/ $4.0 /)$.

\begin{abstract}
The genus Methylophilus uses methanol as a carbon and energy source, which is widely distributed in terrestrial, freshwater and marine ecosystems. Here, three strains $(13,14$ and QUAN) related to the genus Methylophilus, were newly isolated from Lake Fuxian sediments. The draft genomes of strains 13, 14 and QUAN were $3.11 \mathrm{Mb}, 3.02 \mathrm{Mb}, 3.15 \mathrm{Mb}$ with a G+C content of 51.13, 50.48 and 50.33\%, respectively. ANI values between strains 13 and 14, 13 and QUAN, and 14 and QUAN were 81.09, 81.06 and 91.46\%, respectively. Pan-genome and core-genome included 3994 and 1559 genes across 18 Methylophilus genomes, respectively. Phylogenetic analysis based on 1035 single-copy genes and 16S rRNA genes revealed two clades, one containing strains isolated from aquatic and the other from the leaf surface. Twenty-three aquatic-specific genes, such as 2OG/Fe(II) oxygenase and diguanylate cyclase, reflected the strategy to survive in oxygen-limited water and sediment. Accordingly, 159 genes were identified specific to leaf association. Besides niche separation, Methylophilus could utilize the combination of ANRA and DNRA to convert nitrate to ammonia and reduce sulfate to sulfur according to the complete sulfur metabolic pathway. Genes encoding the cytochrome $c$ protein and riboflavin were detected in Methylophilus genomes, which directly or indirectly participate in electron transfer.
\end{abstract}

Keywords: Methylophilus; whole-genome sequencing; comparative genome analysis; pan-genome analysis; orthology analysis; nitrogen metabolism; sulfur metabolism

\section{Introduction}

Methylotrophic bacteria are characterized by their use of reduced carbon substrates (methane, methanol and other methylated compounds) as their sole sources of carbon and energy [1]. These bacteria are divided into facultative (microbes that can use both $\mathrm{C} 1$ and multicarbon compounds as substrates) and obligate (microbes that can only use C1 substrates) methylotrophs [1]. From a phylogenetic point of view, they are affiliated with Alpha-, Beta- and Gammaproteobacteria, Actinobacteria and Verrucomicrobia, respectively [2]. In nature, methylotrophic bacteria are widely distributed in terrestrial habitats (such as wastewater treatment plants [3], wetlands [4], municipal biowaste [5]), freshwater and marine ecosystems, which participate in carbon and nitrogen cycling [6]. As a carbon source, methanol is unique in that it can only be metabolized by methylotrophic bacteria, such as members of the family Methylophilaceae and Methylobacteriaceae [7]. Bioconversion drives sustainable and clean utilization of methanol. Methylotrophic bacteria can be used as hosts to construct cell factories and synthesize amino acids and cell proteins through the abundant one-carbon compounds in nature [8]. In addition, metabolic engineering and synthetic biology strategies are adopted to improve methanol utilization efficiency and promote methanol bioconversion for the Methylotrophs. Thus, it is of great practical significance to study the metabolism of methylotrophic bacteria [9]. 
The genus Methylophilus comprises non-halophilic, obligately and restricted facultatively methylotrophic bacteria [10] belonging to the family Methylophilaceae, order Nitrosomonadales, class Betaproteobacteria and phylum Proteobacteria. Thus far, eight species (Methylophilus aquaticus, M. flavus, M. glucosoxydans, M. leisingeri, M. luteus, M. methylotrophus, M. quaylei and M. rhizosphaerae) are nominated in the genus [10]. They use methanol as a carbon and energy source and oxidize methanol by the catalyst methanol dehydrogenase $(\mathrm{MDH})$, the activity of which is regulated by the type of carbon source [11]. In recent years, worldwide attention has been paid to nonmethanotrophic methanol users because of the increase in methanol emissions (82-273 Tg/year) [6]. Thus the insight into the genus Methylophilus can provide solutions for sustainable utilization of methanol and its industrial application. We aimed to expand the cultivation of this functional group and improve our understanding of its role in lake ecosystems.

Methylophilus species were detected in hyperoxia, hypoxia and anoxia environments, and especially at the interface of hyperoxia-hypoxia [12], indicating that they could survive under oxygen-limited conditions as aerobic bacteria traditionally. Moreover, colonization of Methylophilus spp. in different habitats is the result of mutual adaptation between bacteria and the environment. We expect to enhance the understanding of the survival mechanism of the genus Methylophilus under oxygen-limited conditions. Thus, in this study, three newly isolated methylotrophic strains (Methylophilus sp. 13, Methylophilus sp. 14 and Methylophilus sp. QUAN) were obtained from an enriched culture of Lake Fuxian sediment samples. We speculated that Methylophilus strains isolated from various habitats could harbor differences in their functional gene numbers and categories.

In recent years, with the rapid development of high-throughput sequencing technology, massive amounts of microbial genomic data revealed the possibility of studying various microbes. The advantages of comparative genomic analysis over the conventional approach lie in the ability to guide the discovery of functional genes structure, predict the unique metabolic pathways, and obtain a functional potential for the sequenced microbes. A number of genome sequences available in the public database also provided the opportunity to go deep into the genus Methylophilus. The comparative genomic analysis was performed using three newly isolated Methylophilus strains and the other 15 strains belonging to the genus Methylophilus that had been sequenced and archived in the database to understand genome-level differences and similarities among them. Pan- and core-genome analyses were performed based on average nucleotide identity (ANI) and average amino acid identity (AAI) as well as orthologic, phylogenetic, metabolic and statistical analyses. The comparative genomic analysis could help us better understand the impact of the heterogeneous environment on the genus Methylophilus at the genomic level.

\section{Materials and Methods}

\subsection{Strain Isolation and DNA Extraction}

The samples were taken from the sediment column of Lake Fuxian in Yunnan Province and the enrichment culture of methylotrophs was grown in a liquid medium (NMS), containing (in grams per liter of distilled water) $\mathrm{KNO}_{3}, 1.0 ; \mathrm{KH}_{2} \mathrm{PO}_{4}, 0.35 ; \mathrm{Na}_{2} \mathrm{HPO}_{4} \cdot 12 \mathrm{H}_{2} \mathrm{O}$, $0.65 ; \mathrm{NaHCO}_{3}, 8.4 ; \mathrm{Na}_{2} \mathrm{CO}_{3}, 3.0 ; \mathrm{NaCl}, 7.5 ; \mathrm{MgSO}_{4} \cdot 7 \mathrm{H}_{2} \mathrm{O}, 0.2 ; \mathrm{CaCl}_{2}, 0.02$, with the addition of trace elements in the solution, containing (in grams per liter of distilled water) $\mathrm{Na}_{2} \mathrm{EDTA}$ 0.5; $\mathrm{FeSO}_{4} \cdot 7 \mathrm{H}_{2} \mathrm{O} 0.2 ; \mathrm{H}_{3} \mathrm{BO}_{3} 0.03 ; \mathrm{ZnSO}_{4} \cdot 7 \mathrm{H}_{2} \mathrm{O} 0.01 ; \mathrm{MnCl}_{2} \cdot 4 \mathrm{H}_{2} \mathrm{O} 0.003 ; \mathrm{CaCl}_{2} \cdot 6 \mathrm{H}_{2} \mathrm{O} 0.02$; $\mathrm{CuSO}_{4} \cdot 5 \mathrm{H}_{2} \mathrm{O} 0.03 ; \mathrm{NiCl}_{2} \cdot 6 \mathrm{H}_{2} \mathrm{O} 0.002 ; \mathrm{Na}_{2} \mathrm{MO}_{4} \cdot 2 \mathrm{H}_{2} \mathrm{O} 0.003$. A set of $100 \mathrm{~mL}$ bottles was filled with $20 \mathrm{~mL}$ NMS medium, $5.0 \mathrm{~g}$ wet sediment and $10 \mathrm{~mL} \mathrm{CH}_{4}(10 \%$, v/v) in the headspace. We obtained a number of methanotrophic consortia through long-term incubation at $18{ }^{\circ} \mathrm{C}$ in the laboratory, which mainly consisted of methanotrophs associated with methylotrophs and a few heterotrophic bacteria. The inoculum was routinely transferred once a week. After 10 generations, the culture was taken out from the liquid medium, diluted to about $10^{-3}-10^{-6}$ and isolated by sieving on NMS agar media containing (in grams per liter of distilled water) $\mathrm{KH}_{2} \mathrm{PO}_{4}, 2.0 ;\left(\mathrm{NH}_{4}\right)_{2} \mathrm{SO}_{4}, 2.0 ; \mathrm{MgSO}_{4} \cdot 7 \mathrm{H}_{2} \mathrm{O}, 0.025 ; \mathrm{NaCl}$, $0.5 ; \mathrm{FeSO}_{4} \cdot 7 \mathrm{H}_{2} \mathrm{O}, 0.02$, agar, $1.5 \% \sim 2.0 \%(w / v)$, with the addition of $0.5 \%$ methanol $(v / v)$ as 
a carbon source, which was evenly coated on the surface of agar plates by coating rods after the solidification of NMS agar plates, and inoculated bacteria until methanol was absorbed. Normally after 3-4 times of purification on agar plates, pure Methylophilus colonies could be obtained. By following these steps, three strains Methylophilus sp. 13, Methylophilus sp. 14 and Methylophilus sp. QUAN were obtained from the enrichment consortia.

Genomic DNA was extracted from the cell pellets using a Bacterial DNA Kit (D3350-01, OMEGA) according to the manufacturer's instructions, and quality control was subsequently carried out on the purified DNA samples. Genomic DNA was quantified by using a Qubit3.0 fluorometer (Thermofisher, Waltham, MA USA). A highly qualified DNA sample (OD260/280 = 1.8 2.0, >3 $\mu$ g) was used in further sequencing.

The full-length 16S rRNA gene of the three strains was amplified by PCR with universal primers (27F 5'-AGAGTTTGATCCTGGCTCAG-3'; 1429R 5'-GGTTACCTTGTTACGACTT-3') and sequenced by the Tsingke Biology and Technology Company. The $25 \mu \mathrm{L}$ reaction mixture contained $0.5 \mu \mathrm{L}$ of forward primer $(10 \mu \mathrm{M})$ and $0.5 \mu \mathrm{L}$ of reverse primer $(10 \mu \mathrm{M}), 23 \mu \mathrm{L}$ of T3 Mix enzyme and $1 \mu \mathrm{L}$ of DNA templates. The cycling conditions were $10 \mathrm{~min}$ at $95^{\circ} \mathrm{C}$ for pre-denaturation, followed by 35 cycles of $50 \mathrm{~s}$ at $95^{\circ} \mathrm{C}, 50 \mathrm{~s}$ at $52{ }^{\circ} \mathrm{C}$ for, $90 \mathrm{~s}$ at $72{ }^{\circ} \mathrm{C}$, and a final $10 \mathrm{~min}$ at $72{ }^{\circ} \mathrm{C}$ for extension. The DNA sequence data were analyzed using BLAST software (http:/ / blast.ncbi.nlm.nih.gov / Blast.cgi, 12 July 2019). The phylogenetic position for each strain was determined by comparison with related taxa (11 Methylophilus isolates, 8 Methylophilus type species and 2 Methylotenera strains) obtained from the GenBank database (http:/ / www.ncbi.nlm.nih.gov/, 10 March 2020). A phylogenetic tree was constructed using the neighbor-joining [13] method in MEGAX [14] (version 10.1.8). According to 16S rRNA gene sequence similarity and phylogenetic analysis, 13, 14 and QUAN were classified as belonging to the genus Methylophilus.

\subsection{Genome Sequencing and Assembly}

At least $3 \mu \mathrm{g}$ of genomic DNA were used for library sequencing construction. Pairedend libraries with insert sizes of $\sim 450$ bp were prepared following Illumina's standard genomic DNA library preparation procedure. Briefly, purified genomic DNA was sheared into smaller fragments of a desired size by Covaris, and blunt ends were generated by using T4 DNA polymerase. After adding an " $\mathrm{A}$ " base to the $3^{\prime}$ end of the blunt phosphorylated DNA fragments, adapters were ligated to the ends of the DNA fragments. The desired fragments were purified through gel electrophoresis, then selectively enriched and amplified by PCR. The index tag was introduced into the adapter at the PCR stage as needed, and a library-quality test was done. Finally, the qualified Illumina pair-end library was used for Illumina Miseq sequencing (300bp $\times 2$, Shanghai BIOZERON Co., Ltd., Shanghai, China). The raw paired-end reads were trimmed and quality controlled by Trimmomatic with parameters (Truseq PE adaptors, SLIDINGWINDOW:4:15 MINLEN:75, version 0.36 http: / / www.usadellab.org/cms/uploads/supplementary/Trimmomatic, 7 August 2020). A SPAdes software package was introduced to conduct genome assembly with default parameters [15]. Contigs of fewer than $500 \mathrm{bp}$ were discarded in our study by custom perl scripts. The genomic sequences of three strains $(13,14$ and QUAN) were submitted to the GenBank database under accession numbers GCA_015354335.1, GCA_015354345.1 and GCA_015354445.1, respectively.

\subsection{Gene Prediction and Annotation}

Bacterial gene models were identified using GeneMark (Georgia Institute of Technology, Atlanta, GA, USA) [16]. Then, all gene models were compared using a BLAST against non-redundancy in the NCBI, KEGG (http: / / www.genome.jp/ kegg/, 8 August 2020) and COG (http: / / www.ncbi.nlm.nih.gov/COG, 8 August 2020) databases so that functional annotation by the BLASTp module could be conducted [17]. In addition, tRNA were identified using the tRNAscan-SE (Department of Biomolecular Engineering, University of California Santa Cruz, CA 95064, USA, v1.23, http: / / lowelab.ucsc.edu/tRNAscan-SE, 8 August 2020) and rRNA were determined us- 
ing the RNAmmer (Centre for Molecular Biology and Neuroscience and Institute of Medical Microbiology, University of Oslo, NO-0027 Oslo, Norway, v1.2, http: //www.cbs.dtu.dk/services/RNAmmer/, 8 August 2020).

\subsection{Genome Selection and Phylogenomic Analysis}

The available genomic sequences were downloaded from the NCBI RefSeq database by using "Methylophilus" as the keyword. Among a total of 17 online genomes (until 1 September 2020), GCA_006363915.1 and GCA_006363935.1 represented the same species Methylophilus medardicus, and their sequences were completely identical, so GCA_006363935.1 was discarded in the following analysis. To eliminate any possible errors in further comparative genomic analysis, gene models and other genomic elements like tRNA and rRNA were re-identified by the pipeline described above. We also introduced CheckM software to evaluate the quality of all the genomes in this study [18]. Those with a completeness of less than $75 \%$ or a contamination larger than 5\% were discarded. Therefore, GCA_008015785.1 was also discarded, and the remaining 15 public genomes were analyzed alongside the three genomes obtained in this study (Table 1).

OrthoFinder2 was used to perform a DIAMOND-based all-versus-all gene search on amino acid levels and identified clusters of orthologous genes (OGs) [19,20]. In all, 1035 single-copy OGs were aligned by MUSCLE and concatenated to construct a phylogenetic tree with FastTree under the maximum-likelihood method with Methylotenera versatilis $301^{\mathrm{T}}$ and Methylotenera mobilis JLW8 ${ }^{\mathrm{T}}$ as the outgroup [21,22]. The average nucleotide identity (ANI) was calculated as previously described by FastANI with default parameters [23,24], and average amino acid identities (AAI) were calculated to discriminate among different species and genera. An ANI and AAI heatmap was drawn using the "pheatmap" package in an $\mathrm{R}$ environment.

\subsection{Metabolic and Statistical Analysis}

A metabolic functional gene heatmap and metabolic pathway were constructed using the "pheatmap" package in an R environment and Adobe Illustrator CC 2019, respectively. In addition, histograms were performed to identify the gene number contained in different isolation habitats using GraphPad Prism (version 8.2.1). Ordinary one-way ANOVA was used to analyze significant gene number differences among the different habitats and $95 \%$ confidence intervals were given. 
Table 1. General features of the genomes within the genus Methylophilus.

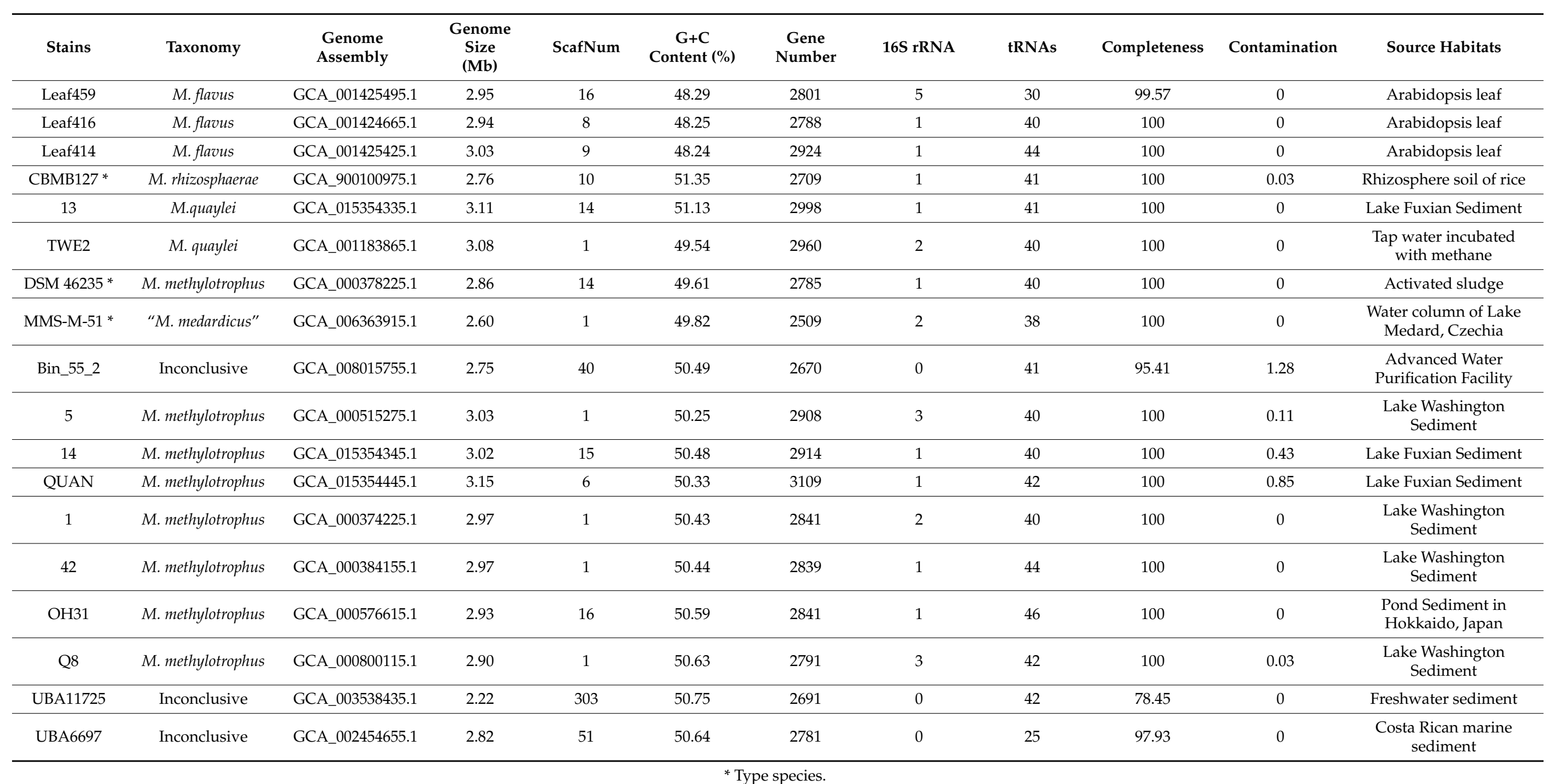




\section{Results}

\subsection{General Genomic Features of the Three New Strains}

The genomic features of the genus Methylophilus are listed in Table 1 . The draft genomic sequences of Methylophilus sp. 13, 14 and QUAN consist of $3.11 \mathrm{Mb}, 3.02 \mathrm{Mb}$ and $3.15 \mathrm{Mb}$, with scaffold numbers of 14, 15 and 6, coverage of 590, 377 and 405-fold, respectively. Compared to the new isolates in this study, the quality of the genomes obtained from the metagenomic assembly pipeline was relatively low. For example, genome completeness was $78.45 \%$ for GCA_003538435. In total, 41, 40 and 42 tRNA genes were detected, and a total of 2998, 2914 and 3109 genes were identified from Methylophilus sp. strains 13, 14 and QUAN, respectively. Moreover, the 16S rRNA gene was assembled in all three genomes with a completeness of $100 \%$.

Phylogenetic analysis was performed based on 16S rRNA genes and the 1035 singlecopy genes to reveal the evolutionary relationship among the 18 Methylophilus strains. The 16S rRNA gene sequence similarity between Methylophilus spp. ranged from 97.17 to $100 \%$ (Figure 1), among which similarities between strains 13 and 14 was $99.28 \%$, strains 13 and QUAN was 99.28\% and strains 14 and QUAN was 100\%. Both Methylophilus sp. 14 and QUAN had 99.52\% 16S rRNA gene similarity with their closest neighbor $M$. methylotrophus NCIMB 10515 ${ }^{\mathrm{T}}$ (AB193724). In addition, Methylophilus sp. 13 has its closest relative Methylophilus quaylei $\mathrm{MT}^{\mathrm{T}}$ (AY772089) with 99.58\% 16S rRNA gene similarity.

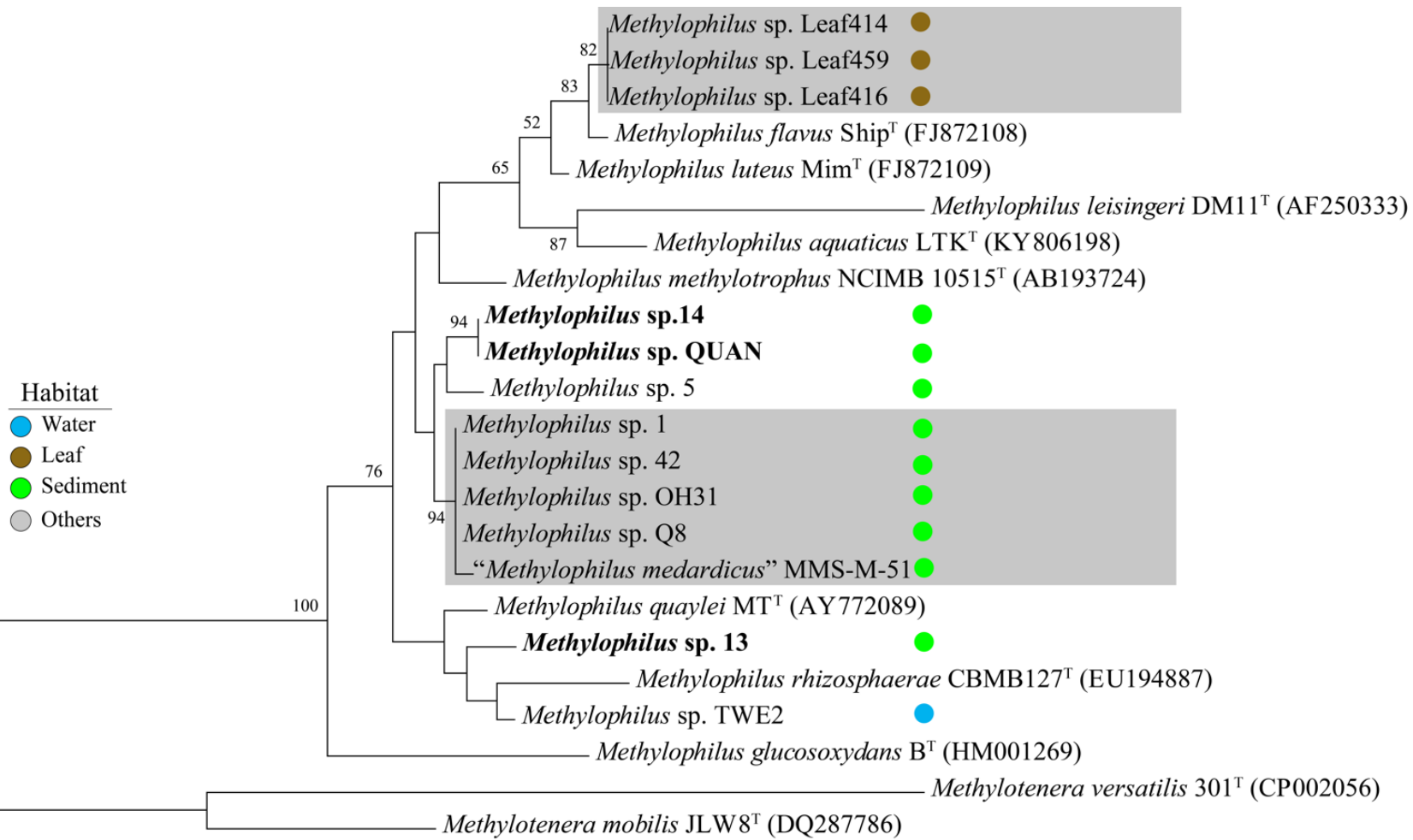

Tree scale : 0.010

Figure 1. Phylogenomic tree based on 16S rRNA genes. The positions of the 13 strains of genus Methylophilus, 8 Methylophilus type strains and 2 Methylotenera strains were shown in the phylogenomic tree and bootstrap values (the percentage of 1000 data resamplings) $\geq 50 \%$ are shown at the nodes based on neighbor-joining method. Three newly isolated methylotrophic strains (Methylophilus sp. 13, 14 and QUAN) were highlighted with bold. The 16S rRNA gene sequences of Methylotenera versatilis $301^{\mathrm{T}}$ and Methylotenera mobilis $\mathrm{JLW} 8^{\mathrm{T}}$ were used as the outgroup. The scale bar represents one substitution per $100 \mathrm{bp}$. The clades belonging to the same species were highlighted with grey according to AAI results (AAI values larger than 95\%), respectively. The solid circles with colors, blue, brown, green and grey, represent isolation sources, water, leaf, sediment and others, respectively. 8 Methylophilus type strains and 2 Methylotenera strains were unlabeled habitat sources. 2 Methylophilus type strains, Methylophilus rhizosphaerae and Methylophilus methylotrophus harbored whole-genome sequences. 
Three newly isolated strains (Methylophilus sp. 13, 14 and QUAN) in this study formed significant new branches in the phylogenomic tree (Figure 2, Supplementary Table S1). The ANI and AAI value between Methylophilus spp. ranged from 78.66 to $99.99 \%, 81.07 \%$ to $100 \%$, respectively. The ANI and AAI value of strain 14 with the closest type strain M. methylotrophus DSM $46235^{\mathrm{T}}$ were 81.69 and $87.03 \%$, respectively. The ANI and AAI value of strain QUAN with the closest type strain $M$. methylotrophus DSM $46235^{\mathrm{T}}$ were 81.92 and $86.95 \%$, respectively. All the values were lower than the species threshold corresponding to 95\% ANI and 90\% AAI. Especially, two strains 14 and QUAN harbored $100 \%$ similarity according to the phylogenetic analysis based on 16S rRNA genes, but phylogenetic analysis based on 1,035 single-copy genes and the ANI results (91.46\%) indicated they diverged into two species, which might be novel species candidates in the genus Methylophilus. Since the genome sequence of $M$. quaylei $\mathrm{MT}^{\mathrm{T}}$ was not available yet, we did not have enough information to decide whether strain 13 would be a novel species candidate.

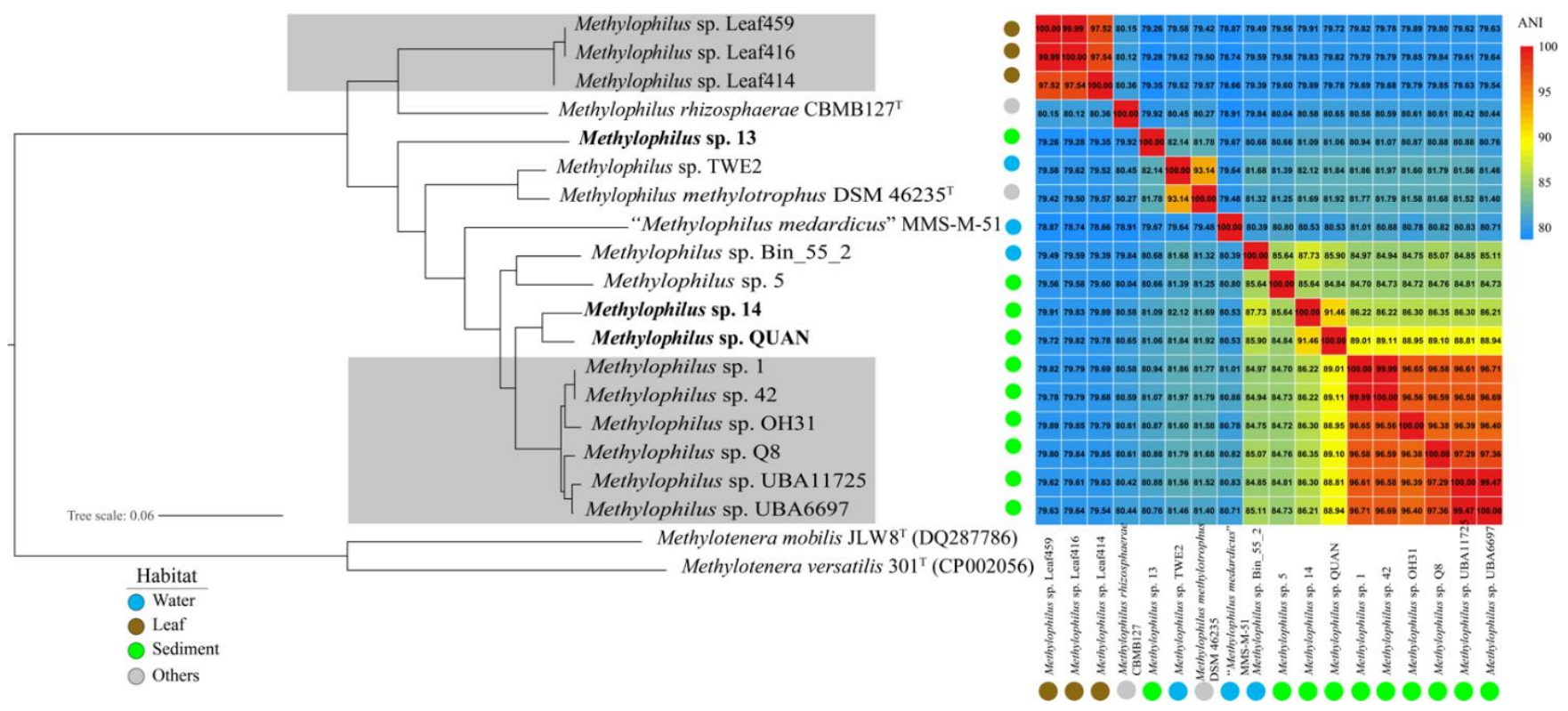

Figure 2. Phylogenomic tree based on 1035 single-copy genes with Methylotenera versatilis $301^{\mathrm{T}}$ and Methylotenera mobilis JLW $8^{\mathrm{T}}$ as the outgroup and ANI heatmap. The positions of the 18 strains of genus Methylophilus and 2 type strains of genus Methylotenera were shown in the phylogenomic tree based on the comparative sequence analysis (1,035 single-copy genes). Three newly isolated methylotrophic strains (Methylophilus sp. 13, 14 and QUAN) were highlighted with bold. The clades belonging to the same species were highlighted with grey according to ANI results (ANI values larger than 95\%), respectively. The solid circles with colors, blue, brown, green and grey, represent isolation sources, water, leaf, sediment and others, respectively. The tree scale (0.06) indicated the number of substitutions per amino acid position. Cells in the heatmap consistent with different ANI values were represented by different color scales.

Among the 18 Methylophilus genomes, six strains (Methylophilus sp. 1, Methylophilus sp. 42, Methylophilus sp. OH31, Methylophilus sp. Q8, Methylophilus sp. UBA11725 and Methylophilus sp. UBA6697) possibly belong to the same species since the intraspecies level is defined at $\geq 95 \%$ ANI [23]; meanwhile, Methylophilus sp. Leaf459, Leaf416 and Leaf414 belong to the same species according to their high ANI values ( $\geq 95 \%$ ANI). In addition, both ANI and AAI analysis supported the finding that the remaining Methylophilus species were differentiated from each other (Figure 2 and Supplementary Figure S1).

These 18 Methylophilus strains were divided into two groups according to their isolated habitats. Methylophilus sp. Leaf459, Leaf416 and Leaf414 were isolated from a terrestrial plant leaf, and the remaining species were isolated from aquatic ecosystems. Furthermore, two subgroups, including lake water and sediment, were identified in the aquatic habitats. 
In addition, $M$ Rhizosphaerae $\mathrm{CBMB} 127^{\mathrm{T}}$ and $M$. methylotrophus DSM $46235^{\mathrm{T}}$ were derived from the rhizosphere soil of rice and activated sludge $[25,26]$, respectively. Apparently, phylogenetic analysis revealed that the strains isolated from the leaf were separated from other related representatives of water and sediment. Notably, the commonness and differences among the strains isolated from various environments required further study.

The GC $\%$ of Methylophilus genomes ranged from 48.24 to $51.35 \%$, with the lowest value belonging to strain Methylophilus. Leaf414, and the highest to Methylophilus. rhizosphaerae strain GCA_900100975.1. A one-way ANOVA for GC\% of genomes isolated from the three habitats (leaf, water and sediment) was performed, and gave $95 \%$ confidence intervals. The strains isolated from leaf had a significantly lower $\mathrm{G}+\mathrm{C}$ content $(\sim 48.26 \%)$ than that of the strains isolated from freshwater or sediment ecosystems $(p<0.0001)$, whereas no difference was identified between water and sediment ecosystems $(p=0.3721)$.

\subsection{Pan-Genome and Orthology Analysis}

The gene number of the Methylophilus genomes selected in this study ranged from 2509 to 3109, with the lowest value belonging to "Methylophilus medardicus" strain GCA_006363915.1, and the highest to Methylophilus sp. QUAN. The total gene number of the pan-genome increased and the number of shared genes (core genome) decreased with the addition of newly sequenced strains, which fit the exponential decaying function [27]. Remarkably, a total of 3994 genes were identified in the pan-genome (Figure 3B). The core genome curve showed that it reached a minimum number of 1559 genes and remained constant (Figure 3C). The singleton gene number ranged from 2 to 362, with the lowest value belonging to Methylophilus sp. 42, and the highest to Methylophilus sp. QUAN. For the three new isolated strains, Methylophilus sp. 13 comprised 326 singleton genes for a total gene number of 2998, whereas the strains 14 and QUAN comprised 202 and 362 singletons, respectively.

We performed a comparison of leaf-specific and aquatic habitat-specific orthogroups (Figure 4, Supplementary Table S2). Specifically, the leaf-specific genomes (Methylophilus sp. Leaf459, Leaf416 and Leaf414) encoded 159 unique genes, such as methyltransferase, exodeoxyribonuclease, acyl carrier protein, aldehyde oxidase and xanthine dehydrogenase, etc. Whereas the aquatic habitat-specific genomes encoded 23 unique genes, such as PEP-CTERM sorting domain-containing protein, metal-dependent phosphohydrolase, an efflux RND transporter permease subunit, sigma-70 family RNA polymerase sigma factor, peptidyl-prolyl cis-trans isomerase, diguanylate cyclase, and poly(3-hydroxybutyrate) depolymerase, etc. It was found that the number of hypothetical proteins specific to the leaf (89 genes) was much higher than those found in aquatic habitats (8 genes). 

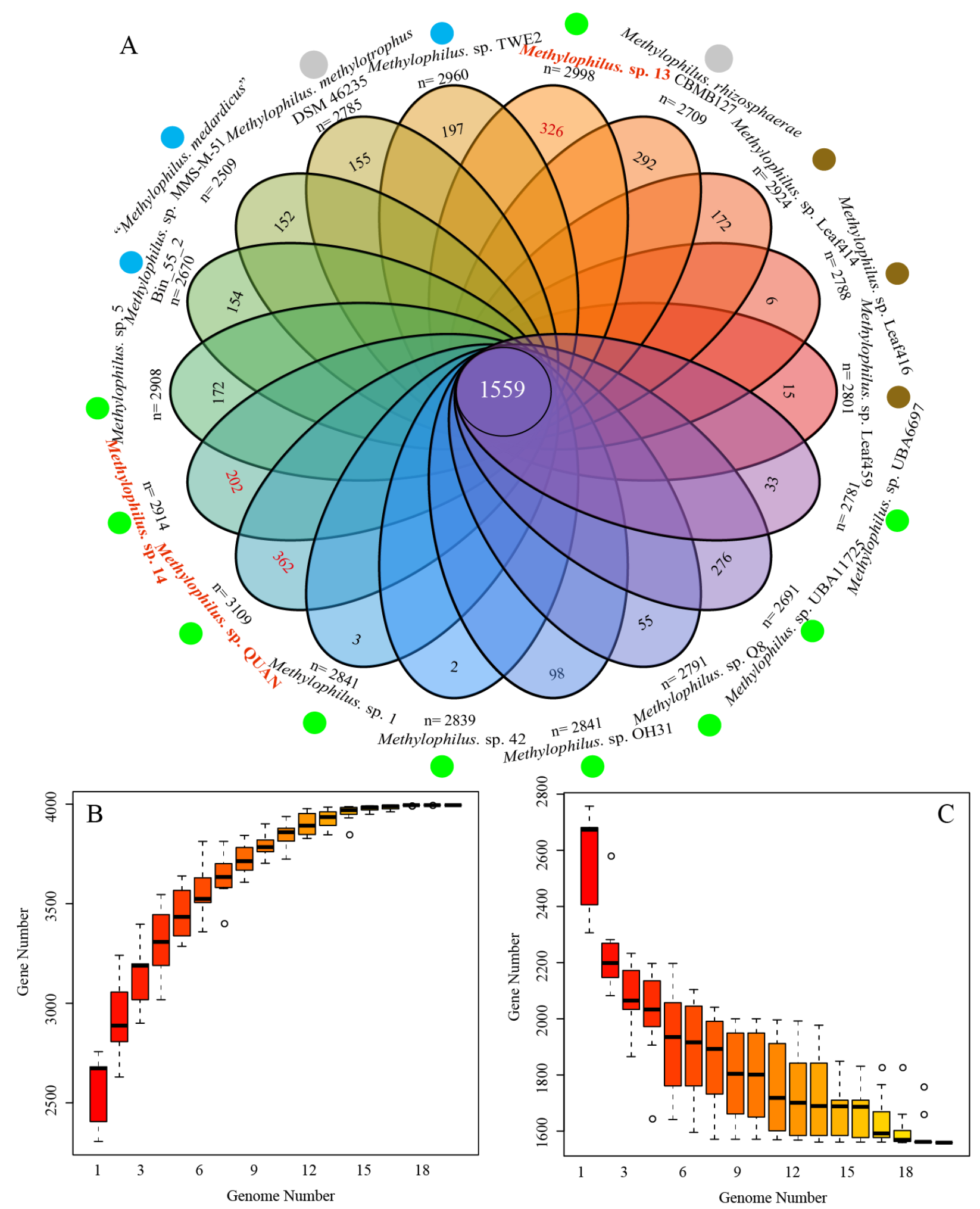

Figure 3. (A) Flower petal plot of 18 Methylophilus genomes. The numbers of yielded unique genes of each strain were shown on the flower petal plot. The center circle indicated the number of core genes obtained from 18 strains. The number below the strain name represented the gene number. The solid circles with colors, blue, brown, green and grey, represent isolation sources, water, leaf, sediment and others, respectively. (B) Pan-genome plot of genus Methylophilus members. It reached a maximum number of 3994 genes. (C) Core-genome plot of genus Methylophilus members. The core genome size is 1559 genes. 


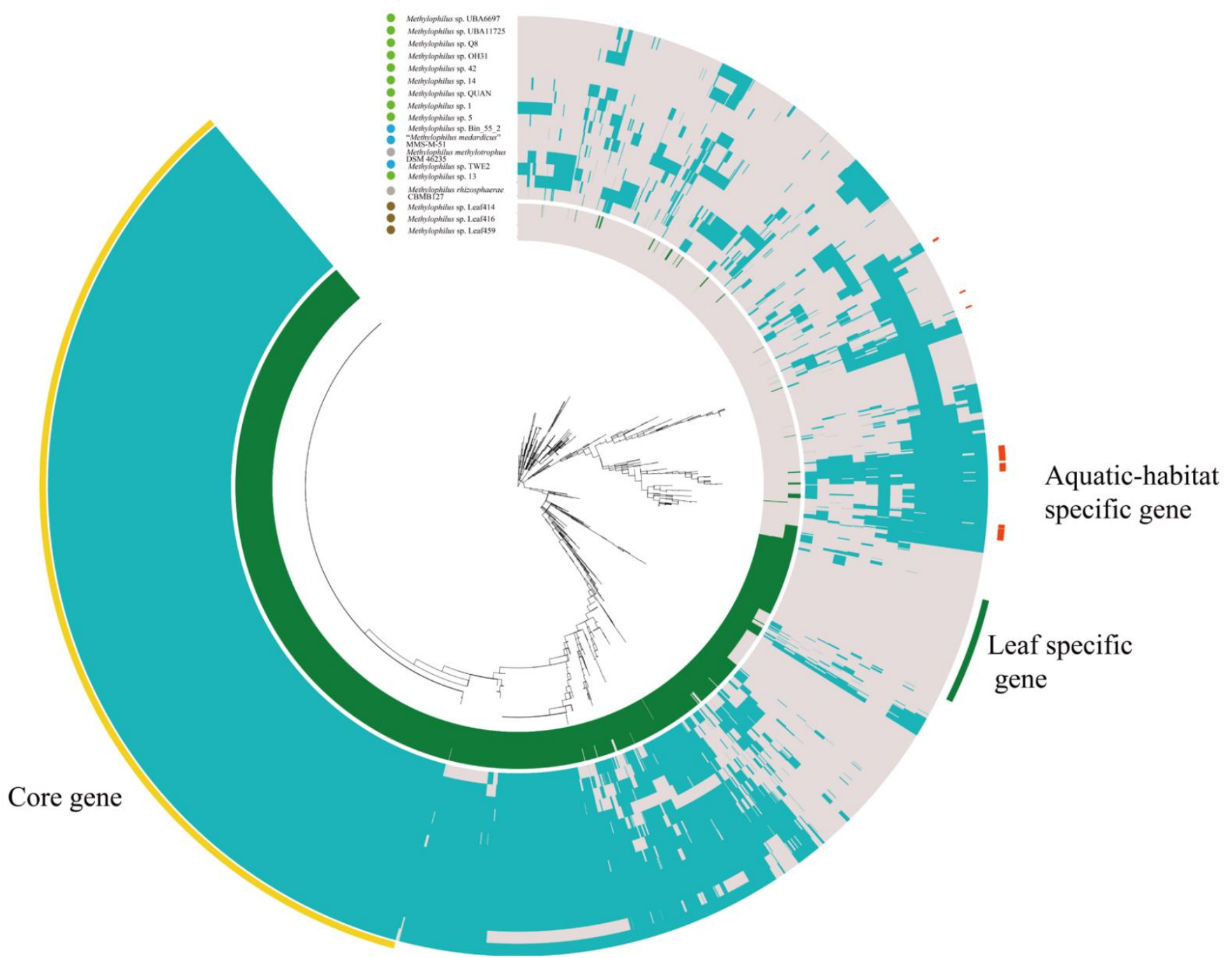

Figure 4. Orthology analysis. Clustering of genomes based on the presence/absence patterns of 3994 orthologous clusters. Genomes of strains isolated from leaf and aquatic habitats (water and sediment) were colored with green and blue in the gene heatmap. Eighteen genomes were defined by the gene tree in the center, and they were organized in radial layers as aquatic-habitat specific gene, leaf specific gene and core gene, which were colored with red, green and yellow. The solid circles with colors, blue, brown, green and grey, represent isolation sources, water, leaf, sediment and others, respectively.

We found that the genes that came from water were similar to those from sediment; that is to say, genes isolated from aquatic habitats harbored high similarity. For example, the genomes of strains isolated from water and sediment both encoded the efflux RND transporter permease subunit, which belongs to the resistance-nodulation-cell division (RND) family. The genomes encoding the MgtC family protein were present in the aquatic habitat ecosystem, which is the virulence factor required for growth in a low $\mathrm{Mg}^{2+}$ medium and for intramacrophage survival and may be involved in regulating membrane potential by activating $\mathrm{Na}^{+} / \mathrm{K}^{+}$-ATPase. The RNA polymerase sigma factor, cytochrome $c$ peroxidase, a DNA-binding protein, and the outer membrane protein TolC were all encoded by aquatic habitat-specific genomes. Besides their high similarity, the water and sediment environments also comprised specific genes ( 1 and 2 genes, respectively, Supplementary Table S2). In summary, the strains isolated from the leaf and aquatic habitats showed differences in functional genes, and the strains isolated from water and sediment had a high similarity on the whole, even if differences existed. 


\subsection{Metabolic Analysis}

\subsubsection{Methanol Metabolism}

In methanol metabolism, genes for the functioning of tetrahydromethanopterin $\left(\mathrm{H}_{4} \mathrm{MPT}\right)$ were present (Figure 5A,B). Periplasmatic pyrroloquinoline quinone (PQQ)dependent methanol dehydrogenase (MDH), which converts methanol to formaldehyde, containing a gene cluster $(m x a A / C / D / G / I / J / K / L)$, was found [7]. Formaldehyde can be converted to format through a $\mathrm{H}_{4} \mathrm{MPT}$-dependent pathway containing a series of processes catalyzed by enzymes, including $f a e, m t d B, m c h, f t r$ and $f w d A / B / C$. Notably, these genes were detected in all genomes, indicating that $\mathrm{H}_{4} \mathrm{MPT}$ was the most significant pathway in the methanol metabolism of Methylophilus. Moreover, genomes isolated from the same source tended to have uniform gene clusters, indicating that they had a functional similarity in methanol metabolism. Genes encoding trimethylamine monooxygenase ( $\mathrm{tmm}$ ), dimethylamine-trimethylamine dehydrogenase $(d m d-t m d)$, methylamine-glutamate Nmethyltransferase $(m g s A / B / C)$ and methylamine dehydrogenase $(m a u A / B)$ were found in the sedimentary environment, which provided a way to convert trimethylamine $\mathrm{N}$-oxide to formaldehyde under anaerobic conditions [28] (Figure 5C). Genes encoding $\mathrm{mfnD} / \mathrm{F}$ were distinctly identified in the leaf ecosystem, which catalyzed the processes of producing methanofuran (MFR). Additionally, genes encoding $m f n D$ presented significant differences among environments (Figure 5C, Supplementary Table S3). In summary, the Methylophilus strains use methanol via MDHs, convert trimethylamine $\mathrm{N}$-oxide to formaldehyde under the anaerobic environment, and then metabolize formaldehyde through the $\mathrm{H}_{4} \mathrm{MPT}$ pathway [29].
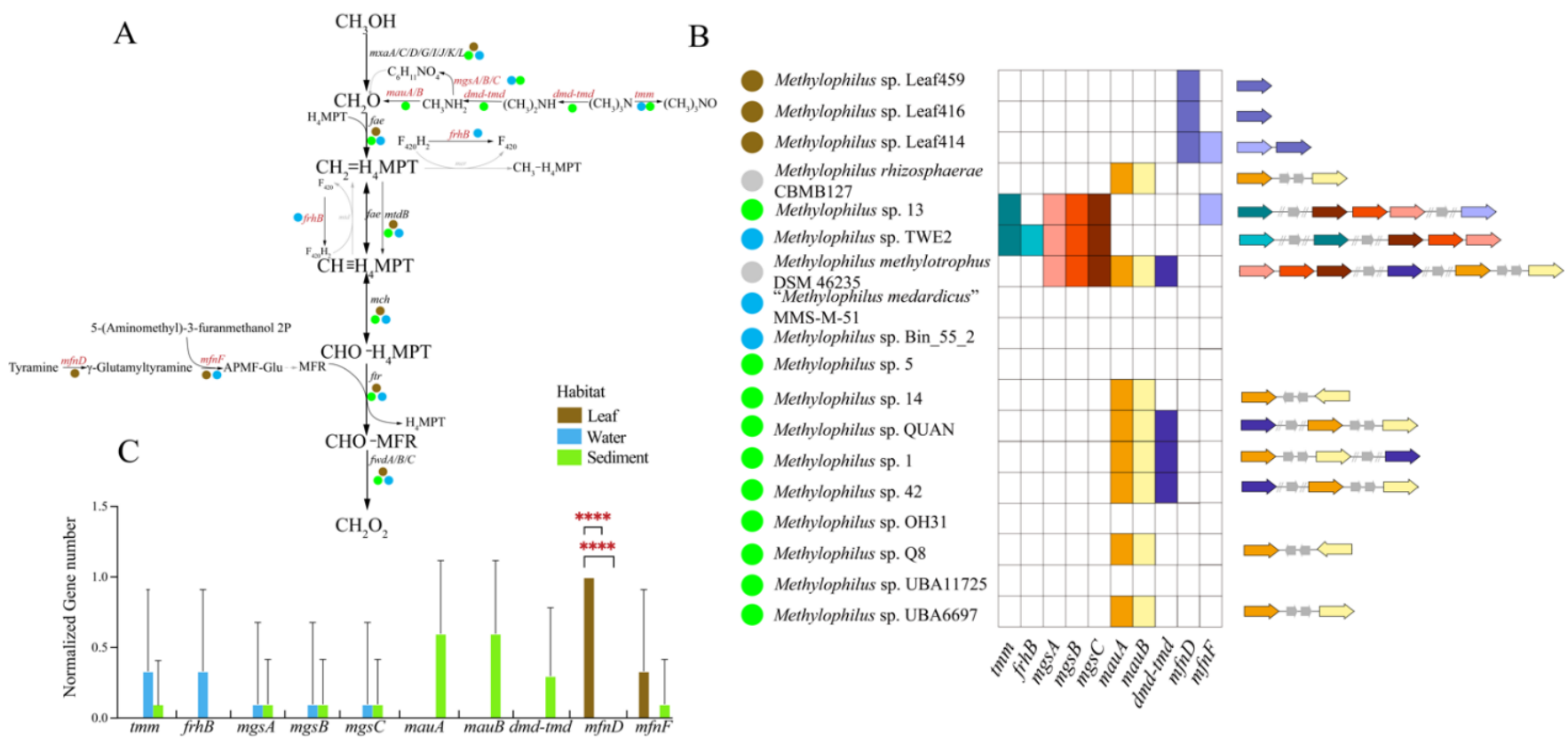

Figure 5. (A) Methanol metabolic pathway. Each step of the reaction is tagged with the corresponding genes. Genes that are present in all genomes are highlighted in black, while those that are present in partial genomes and absent in all of the genomes are highlighted in red and grey, respectively. (B) Distribution of partial methanol metabolism genes in Methylophilus genomes. The colored boxes indicate that the gene is present in the genome, whereas the white box indicates that it is absent. A functional gene clusters structural plot was performed according to the heatmap. The colored arrows correspond to the colored boxes. The grey arrows represent unknown genes. The solid circles with colors, blue, brown, green and grey, represent isolation sources, water, leaf, sediment and others, respectively. (C) Histogram constructed by computing the normalized number of partial methanol metabolism genes involved in (B). Three box colors represented three environments. Significant differences in $m f n D$ gene between leaf versus water and leaf versus sediment by one-way ANOVA. ${ }^{* * *}: p<0.00001$ 


\subsubsection{Carbohydrate-Active Enzymes Analysis}

The CAZy (Carbohydrate-Active enZYmes) database provided significant genome analysis by family distribution and associated proteins identified in genomes. The enzyme classes currently covered six modules: GHs (glycoside hydrolases), GTs (glycosyl transferases), PLs (polysaccharide lyases), CEs (carbohydrate esterases), AAs (auxiliary activities) and CBMs (carbohydrate-binding modules). The heatmap was conducted according to the CAZy results (Supplementary Figure S2), which suggested a greater accumulation of carbohydrate-active enzymes in the leaf habitat. We identified 5 CAZy families specific to the leaf specific genomes, including 3 CEs (CE1/4/10), 1GTs (GT2) and 1 AA (AA12). Only one CAZy family (CE1) was specific to aquatic-habitat genomes (Supplementary Table S2).

\subsubsection{Nitrogen Metabolism}

The Methylophilus genomes harbored genes involved in denitrification (norB), assimilatory nitrate reduction (nas $A)$ and dissimilatory nitrate reduction $($ nirB/D) as well as genes that encode carbonic anhydrase (cynT/cah), cyanate lyase (cynS), and nitrate/nitrite transport system substrate-binding protein ( $N R T / n r t A / n r t B / n r t C$; Figure $6 \mathrm{~A})$. Genomes isolated from the same habitats tended to have uniform gene clusters, indicating that they had a functional similarity in nitrogen metabolism (Figure 6B). Genes encoding the nitrate/nitrite transport system (NRT/nrt $A B C$ ), which can transport extracellular nitrate into cells, were identified in all Methylophilus genomes except $M$. rhizosphaerae. The assimilatory nitrate reductase catalytic subunit A (nasA), which participated in reducing nitrate to nitrite, was identified specifically in water and sediment strains (Figure $6 \mathrm{C}$ ). Genes encoding nir $B D$, which can reduce nitrite to ammonia, were present in strains isolated from all three sources. The above findings suggested that Methylophilus might metabolize nitrate by using assimilatory nitrate reduction combined with dissimilatory nitrate reduction to produce ammonia, the essential nitrogen source for growth. Genes encoding nitric oxide reductase (norB), which can reduce nitric oxide to nitrous oxide, were only present in strains isolated from leaf and sediment. Methylophilus genomes also encoded two carbonic anhydrases (cah and $c y n T$ ) and one cyanate lyase (cynS), which was involved in a cyanate degradation pathway. Additionally, genes encoding nas $A$ and nor $B$ presented significant differences among environments (Figure 6C, Supplementary Table S3). 
A

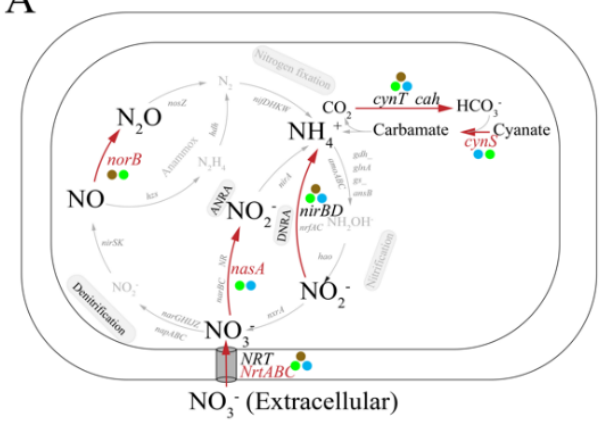

C

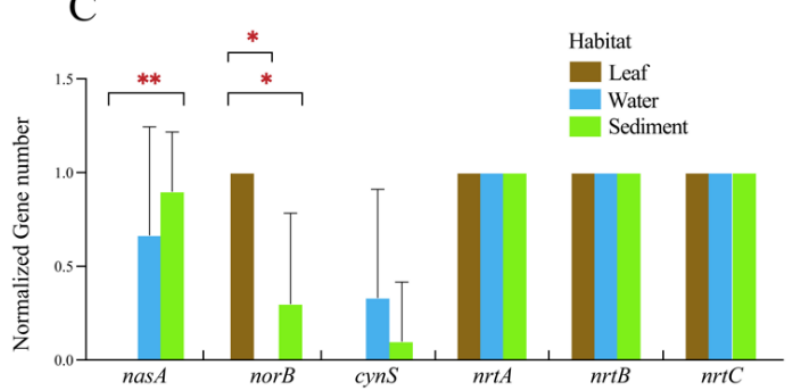

B

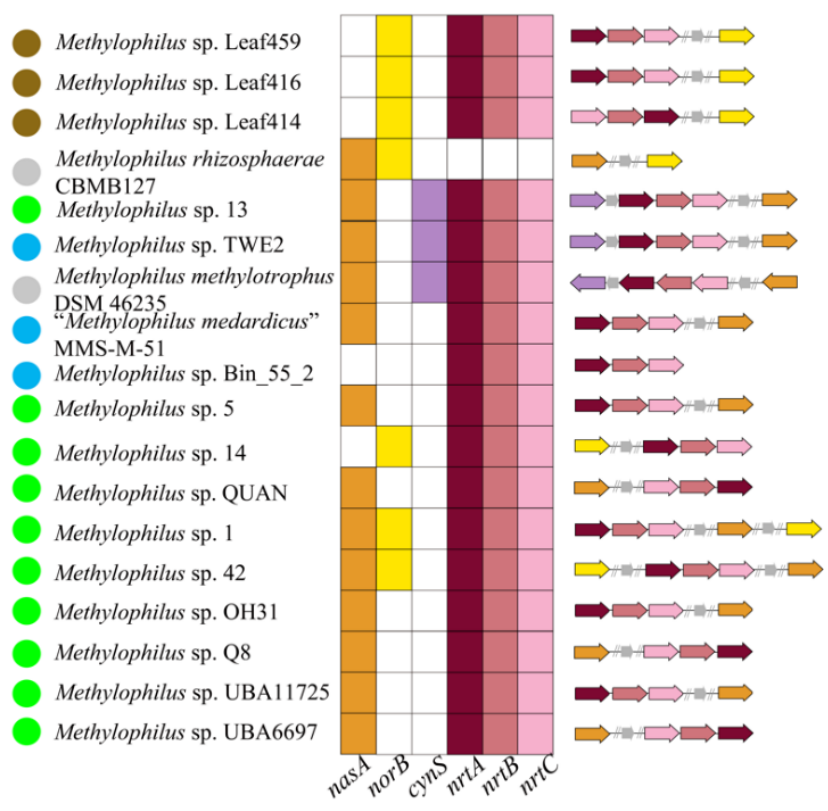

Figure 6. (A) Nitrogen metabolic pathway. Each step of the reaction is tagged with the corresponding genes. Genes that are present in all genomes are highlighted in black, while those that are present in partial genomes and absent in all of the genomes are highlighted in red and grey, respectively. (B) Distribution of partial nitrogen metabolism genes in Methylophilus genomes. The colored boxes indicate that the gene is present in the genome, whereas the white box indicates that it is absent. Functional gene clusters structural plot was performed according to the heatmap. The colored arrows correspond to the colored boxes. The grey arrows represent unknown genes. The solid circles with colors, blue, brown, green and grey, represent isolation sources, water, leaf, sediment and others, respectively. (C) Histogram constructed by computing the normalized number of partial nitrogen metabolism genes involved in (B). Three box colors represented three environments. Significant differences in nas $A$ gene between leaf versus sediment and in nor $B$ gene between leaf versus sediment and water versus sediment by One-Way ANOVA. **: $p<0.01 ; *$ * $p<0.05$.

\subsubsection{Sulfur Metabolism}

Genes for the function of sulfur metabolism were presented in Methylophilus genomes (Figure 7A). The sulfur-oxidizing protein $\operatorname{sox} Y$, assimilatory sulfate reduction (Cys) operon, cytochrome subunit of sulfide dehydrogenase $f c c A$, sulfate transport system substratebinding protein $s b p$, sulfide quinone oxidoreductase $s q r$ and dimethylsulfone monooxygenase $s f n G$ genes were detected in all three environments, suggesting that Methylophilus can synthesize sulfur-containing proteins. Genomes isolated from the same source tended to have uniform gene clusters, indicating that they had a functional similarity in sulfur metabolism (Figure 7B). The sulfide quinone oxidoreductase (sqr), which is involved in the oxidation of reduced sulfur, is responsible for oxidizing sulfide ( $\mathrm{HS}^{-}$) to elemental sulfur $\left(\mathrm{S}_{0}\right)$ [30]. Additionally, ssuC gene encoding sulfonate transport system permease protein harbored significant variation among environments (Figure 7C, Supplementary Table S3). Therefore, the Methylophilus strains can use some sulfur compounds and play a role in the sulfur cycle as the complete sulfur metabolic pathway has been found in the genomes. 
A

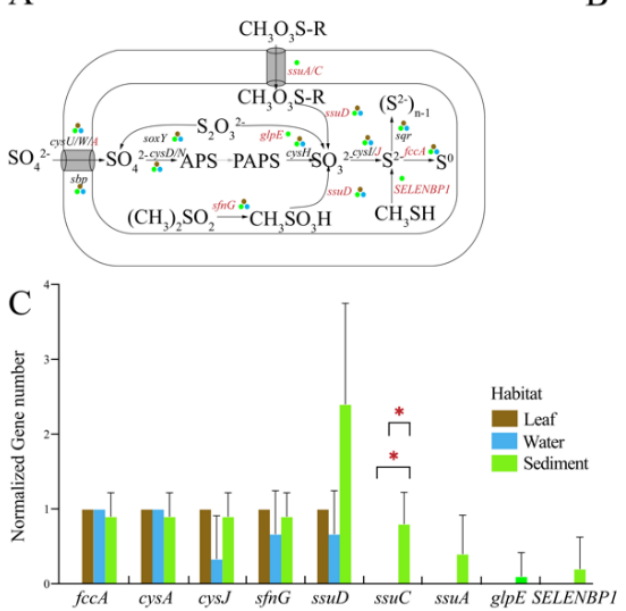

B

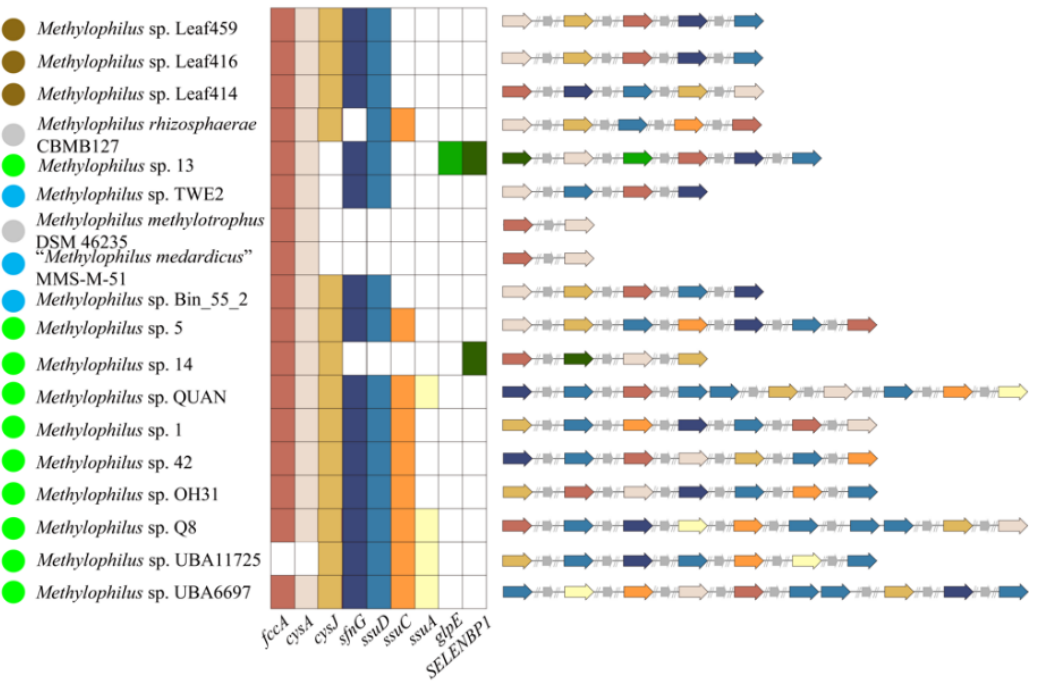

Figure 7. (A) Sulfur metabolic pathway. Each step of the reaction is tagged with the corresponding genes. Genes that are present in all genomes are highlighted in black, while those that are present in partial genomes are highlighted in red. (B) Distribution of partial sulfur metabolism genes in Methylophilus genomes. The colored boxes indicate that the gene is present in the genome, whereas the white box indicate that is absent. Functional gene clusters structural plot was performed according to the heatmap. The colored arrows correspond to the colored boxes. The grey arrows represent unknown genes. The solid circles with colors, blue, brown, green and grey, represent isolation sources, water, leaf, sediment and others, respectively. (C) Histogram constructed by computing the normalized number of partial sulfur metabolism genes involved in (B). Three box colors represented three environments. Significant differences in ssuC gene between leaf versus sediment and water versus sediment by one-way ANOVA. *: $p<0.05$.

\subsubsection{Cellular Electron Transfer for Respiration}

Studies have shown that the respiration of cellular electron acceptors provides a strategy for the study of microbial survival mechanisms under oxygen-limited conditions [31]. Based on genomic analysis, cytochrome $c$ and riboflavin were found to be involved in cellular mineral respiration, which is the basis for cellular electron transfer between minerals and microorganisms [32].

In our study, genes encoding the cytochrome $c$ protein were identified in 18 genomes, such as cytochrome $c$ oxidase $(c c o P / O / N, \operatorname{cox} 11 / 15 / A / B / C)$, cytochrome $c$ reductase $(C Y C 1$, $c y t B$ ) and cytochrome $c$ protein $(C Y C)$ (Figure 8). Additionally, the genes mentioned above (except $C Y C$ ) were identified in all genomes across the three habitats, indicating that Methylophilus can mediate cellular electron transfer for respiration via cytochrome $c$ proteins. As a common electron shuttle, riboflavin provides the approach to shorten the distance between minerals and microorganisms, and enhances the ability of electron transfer [33]. Additionally, genes encoding riboflavin, which indirectly mediates electron transfer, were detected in the genomes, such as GTP cyclohydrolase II (ribA), 3,4-dihydroxy 2-butanone 4-phosphate synthase (ribBA), 5-amino-6-(5-phosphoribosylamino) uracil reductase (ribD), 6,7-dimethyl-8-ribityllumazine synthase ( $\mathrm{ribH}$ ), riboflavin synthase (ribE) and riboflavin kinase/FMN adenylyltransferase ( $r i b F)$. The genes mentioned above were found to exist in all three environments, which suggested that Methylophilus can provide a potential pathway for riboflavin biosynthesis, thus mediating cellular electron transfer through soluble shuttle proteins. According to the statistical analysis performed via one-way ANOVA (Figure 8, Supplementary Table S3), genes encoding cytochrome $c$ and riboflavin proteins were not significantly different among habitats except for the CYC gene (cytochrome $c$ ), which presented significant differences between leaf and sediment. 


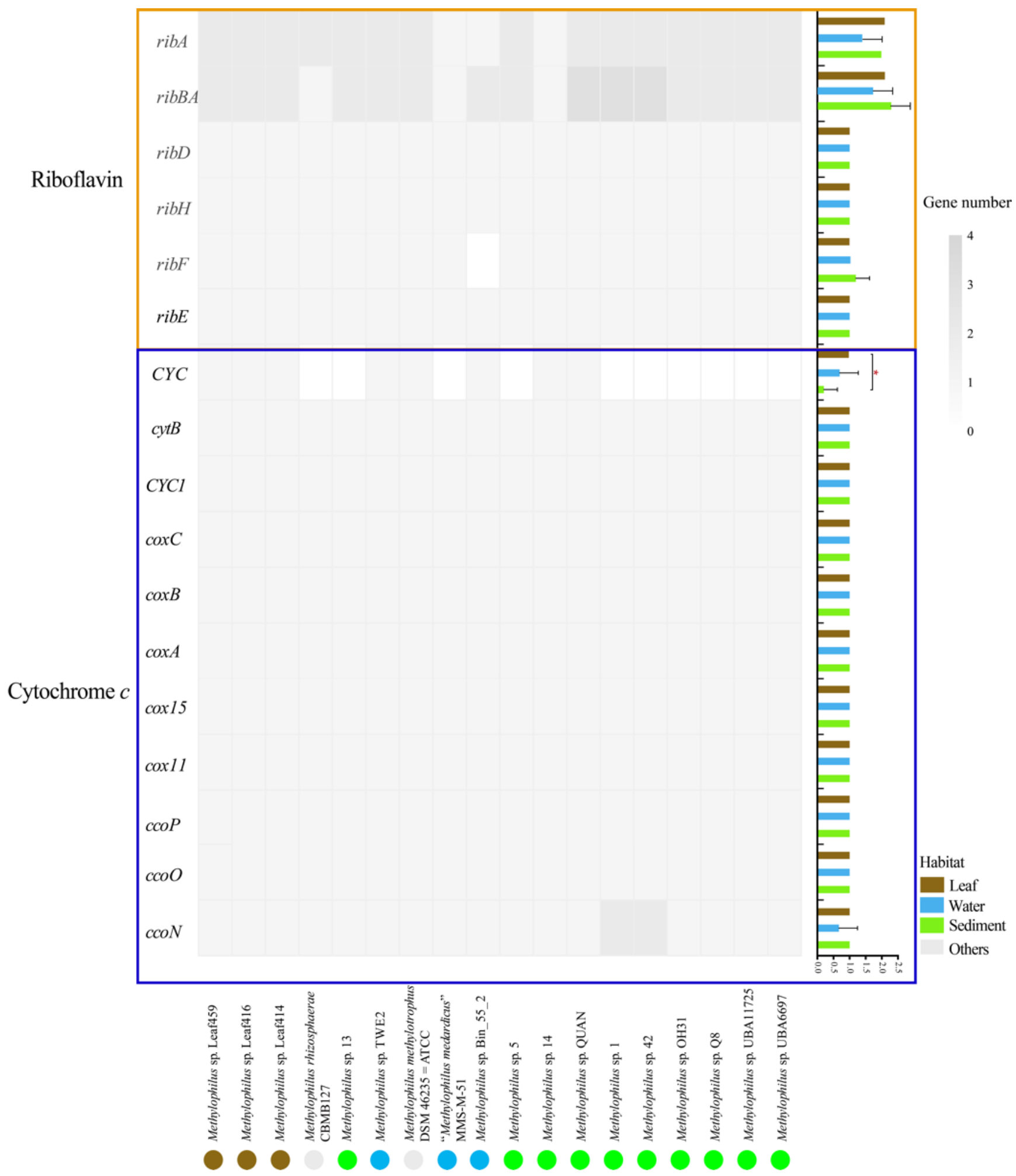

Figure 8. Distribution of genes encoding cytochrome $c$ and riboflavin in Methylophilus genomes. The colored boxes indicate that the gene is present in the genome, whereas the white box indicates that it is absent. The solid circles with colors, blue, brown, green and grey, represent isolation sources, water, leaf, sediment and others, respectively. The histogram was constructed by computing the normalized number of all genes encoding cytochrome $c$ and riboflavin. Three box colors represented three environments. The boxplots were constructed by computing all gene numbers. Three box colors represented three environments. Significant differences in CYC gene between leaf versus sediment environment by one-way ANOVA. *: $p<0.05$. 
In summary, the genes encoding cytochrome $c$ and riboflavin were detected in the genus Methylophilus, which provide the blueprint for the study of the cellular electron transfer mechanism. Additionally, this study provided new insights into the metabolic capacity of methylotrophic bacteria and their survival mode in an oxygen-limited environment, and highlighted the significance of studying the cellular electron transfer mechanism for further exploration of their ecological role.

\section{Discussion}

In this study, all the sequenced genomes of Methylophilus obtained from the GenBank database received attention and a comparative genomic analysis was conducted from the perspective of the pan-genome. The analysis of newly isolated strains in this study (Methylophilus sp. 13, Methylophilus sp. 14, Methylophilus sp. QUAN) along with other 15 strains belonging to the genus Methylophilus, provided insight into the niches separation of Methylophilus spp.

\subsection{Adaptation to Specific Habitats from Genomic View}

Genomes obtained from the three environments were significantly different from each other, especially in the encoding of enzymes. The habitat-specific genes encoding relevant enzymes within the genus Methylophilus might be the results of the adaptation to their environment. The genus Methylophilus could survive hyperoxia, hypoxia and anoxia environments, especially under oxygen-limited conditions [12]. Hydroxylation is an important bacterial regulation mechanism, and the response of hydroxylases to hypoxic conditions makes them an ideal substance for regulating cell response to environmental changes [34]. Protein hydroxylases, which could oxidize the $\mathrm{C}-\mathrm{H}$ bond into a $\mathrm{C}-\mathrm{OH}$ group in an amino acid side chain, belong to 2-oxoglutarate (2OG)/Fe(II) dependent oxygenase family of proteins [35]. The genes encoding 2-oxoglutarate (2OG)/Fe(II) oxygenase detected in aquatic-specific genes of the genus Methylophilus can make it achieve hydroxylation process and survive under hypoxic conditions. In addition, biofilms were known to promote the transfer of electrons from cellular to extracellular conditions by binding to selfsecreted redox-active compounds such as cytochrome $c$ and riboflavin [36,37]. Diguanylate cyclase catalyzes the synthesis of cyclic guanosine monophosphate (c-di-GMP), which plays a key role in the regulation of biofilm formation in bacteria [38]. Matsumoto et al. [39] indicated that the intracellular level of c-di-GMP was sufficient for the expression of extracellular electron transfer (EET)-related genes. We detected genes encoding diguanylate cyclase in aquatic-specific genes, which enabled the genus Methylophilus to use alternative electron acceptors instead of oxygen for EET under the hypoxic conditions, so as to survive in the aquatic environment.

We detected genes encoding acyltransferase, which participated in the transport of lipoproteins from the intima to the outer membrane in leaf-specific genes. We speculated that they play an important role in the colonization and survival of the genus Methylophilus in leaf habitats. Kovacs-Simon et al. [40] indicated that bacterial lipoproteins have a variety of functions, including membrane synthesis, signal transduction, bacterial adhesion, etc. In general, lipoproteins are transported to the extracellular membrane via the transport system to perform their physiological functions and play an important role in bacterial colonization on the host. Lipoproteins have been found in a variety of bacteria. Roussel-Jazede et al. (2011) and Coutte et al. (2003) found that the NalP protein of Neisseria meningitidis and SphB1 protein of Bordetella pertussis contain the secretion signal and self-transporter protein structure of lipoprotein $[41,42]$. They were transported to the outer membrane by the Type V secretory pathway.

\subsection{The Elemental Metabolism Feature of Methylophilus}

In Methylophilus genomes, genes including nor $B$, nas $A$ and nirB/D were involved in denitrification, assimilatory nitrate reduction and dissimilatory nitrate reduction, respectively. We speculated that the Methylophilus strains reduced nitrate to ammonia by a combina- 
tion of assimilatory and dissimilatory nitrate reduction and took ammonia as the critical nitrogen source in three ecosystems. While, species in the adjacent genus Methylotenera reduced nitrate to nitrogen by denitrification, which differentiates from Methylophilus [43]. Microorganisms have great diversity in nitrogen transformation, and each of them has its own optimal growth conditions [44]. In the microbial nitrogen-cycling network, it needs a lot of energy consumption to reduce nitrate to nitrogen by denitrification, as more ATP is in need for electron transfer under a long electron transfer chain [44]. We speculated that Methylphilus performed nitrate respiration under hypoxic conditions with less energy consumption via the combination of DNRA and ANRA. Notably, genes encoding nitrite reductase (nirSK) were not identified in the nitrogen metabolism of all the 18 genomes. However, seven of the 18 genomes, including strains isolated from leaf and sediment, encoded nor $B$ genes, which indicates a distinct feature in nitric oxide reduction to nitrous oxide, a notable greenhouse gas. As for the source of nitric oxide, we speculated that it was produced by other microorganisms co-occurring in the methanotrophic consortia.

In this study, a distinct way in methanol metabolism was detected to convert trimethylamine $\mathrm{N}$-oxide to formaldehyde in strains from the sedimentary habitats. Trimethylamine $\mathrm{N}$-oxide can participate in microbial respiration as an alternative electron acceptor under anaerobic conditions and then be reduced to formaldehyde for further metabolism [28]. This provided some hints for the survival mechanism of the genus Methylphilus in the anaerobic sedimentary environment. In addition, genes encoding enzymes that catalyzed the conversion of sulfate to sulfur were identified in Methylophilus genomes, indicating that strains might also use sulfate as an alternative electron acceptor under the oxygendepleted condition. Moreover, many genes existed in clusters in the genomes, and the integrity of the clusters affected methanol, nitrogen and sulfur metabolism. For example, the mxaACKLD-mxaIGJ operon, including eight methanol oxidation genes, was present in the Methylophilus genomes. Notably, besides the MxaI gene encoding beta subunit of $\mathrm{MDH}$, we only found a gene containing a PQQ-like domain adjacent to the cytochrome $c_{L}$ $(m x a G)$ gene in Methylophilus genomes, which was poorly characterized. We speculated that it might be the synonym of the MoxF/MxaF gene encoding the alpha subunit of MDH to complete the process of methanol oxidation.

In summary, comparative genomics can identify coded, non-coded, and endemic sequences by comparing the genomes of different related species, which is advantageous for genomic analysis; specifically, both intraspecific and interspecific genomic comparisons can be carried out to provide the foundation for future research on other methylotrophic bacteria, such as Methylotenera, Methylovorus and Methylobacillus. According to the analysis, Methylophilus can use single-carbon compounds (methanol) as a carbon and energy source, and drive sustainable and clean utilization of it, such as building cell factories as hosts and synthesizing amino acids and cell proteins. In addition, artificially constructed methylotrophs can improve methanol utilization efficiency and promote methanol bioconversion. Thus it is of great practical significance to study the metabolism of Methylophilus. With the completion of the whole-genome sequencing of increasing Methylophilus strains, bioinformatics, transcriptome and proteomics can also be used to study their metabolic pathways using genomic information [45]. The complete genomic sequences provided the possibility of further research of the genus Methylophilus and other related methylotrophs.

\section{Conclusions}

In this study, the genus Methylophilus was investigated using comparative genomic analysis, and three newly isolated strains were obtained using the enrichment culture. The analysis indicated that there were differences among strains from different environments (leaf, water and sediment). In addition, the Methylophilus genomes consisted of gene inventories related to the metabolism of nitrogen, methanol and sulfur and cellular electron transfer mechanism. However, in the genus Methylophilus, part of the genes responsible for metabolism was absent, thus showing that it had metabolic restrictions. Thus, the functional genes of isolated strains deserve more attention to identify the specific metabolic 
process. To sum up, this study enhanced our understanding of the fundamental genomic features of the genus Methylophilus and the impact of heterogeneous environment on the genus Methylophilus at the genomic level, revealed the mutual adaptation between the genus Methylophilus and different environments and the potential survival mechanism of it under anaerobic conditions, providing insights into methylotrophic bacteria.

Supplementary Materials: The following are available online at https: / www.mdpi.com/article / 10.3390/microorganisms9081577/s1, Figure S1: AAI heatmap, Figure S2: Heatmap conducted according to CAZy results, Table S1: 16S rRNA gene sequence similarity and ANI values, Table S2: Specific genes of 18 genomes among various environments, Table S3: Statistical analysis data in methanol metabolism, nitrogen metabolism, sulfur metabolism and cellular electron transfer mechanism.

Author Contributions: Conceptualization, N.L. and P.X.; methodology, Y.T. and P.G.; software, N.L.; validation, N.L., Y.T., and P.X.; formal analysis, N.L.; investigation, Y.T.; resources, P.X.; data curation, Y.T.; writing-original draft preparation, N.L.; writing-review and editing, P.X. and Y.X.; visualization, N.L. and Y.T.; supervision, P.X.; project administration, P.X.; funding acquisition, P.X. All authors have read and agreed to the published version of the manuscript.

Funding: This research was funded by the National Natural Science Foundation of China (No. 91751111; 31730013; 31670508) and the Youth Innovation Promotion Association of CAS (2014273).

Institutional Review Board Statement: Not applicable.

Informed Consent Statement: Not applicable.

Data Availability Statement: The genomic sequences of three strains (sp. 13, 14 and QUAN) in this study were submitted to the GenBank database under accession numbers GCA_015354335.1, GCA_015354345.1, and GCA_015354445.1, respectively.

Conflicts of Interest: The authors declare no conflict of interest. The funders had no role in the design of the study; in the collection, analyses, or interpretation of data; in the writing of the manuscript, or in the decision to publish the results.

\section{References}

1. Chistoserdova, L.; Kalyuzhnaya, M.G.; Lidstrom, M.E. The expanding world of methylotrophic metabolism. Annu. Rev. Microbiol. 2009, 63, 477-499. [CrossRef]

2. Dunfield, P.F.; Yuryev, A.; Senin, P.; Smirnova, A.V.; Stott, M.B.; Hou, S.; Ly, B.; Saw, J.H.; Zhou, Z.; Ren, Y.; et al. Methane oxidation by an extremely acidophilic bacterium of the phylum Verrucomicrobia. Nature 2007, 450, 879-882. [CrossRef]

3. Kim, I.T.; Lee, Y.E.; Jeong, Y.; Yoo, Y.S. A novel method to remove nitrogen from reject water in wastewater treatment plants using a methane- and methanol-dependent bacterial consortium. Water Res. 2020, 172, 115512. [CrossRef]

4. Vuilleumier, S.; Ivos, N.; Dean, M.; Leisinger, T. Sequence variation in dichloromethane dehalogenases/glutathione S-transferases. Microbiology 2001, 147, 611-619. [CrossRef] [PubMed]

5. Tsapekos, P.; Khoshnevisan, B.; Zhu, X.; Zha, X.; Angelidaki, I. Methane oxidising bacteria to upcycle effluent streams from anaerobic digestion of municipal biowaste. J. Environ. Manag. 2019, 251, 109590. [CrossRef] [PubMed]

6. Chistoserdova, L.; Lapidus, A.; Han, C.; Goodwin, L.; Saunders, L.; Brettin, T.; Tapia, R.; Gilna, P.; Lucas, S.; Richardson, P.M.; et al. Genome of Methylobacillus flagellatus, molecular basis for obligate methylotrophy, and polyphyletic origin of methylotrophy. J. Bacteriol. 2007, 189, 4020-4027. [CrossRef]

7. Dai, Z.; Guo, F.; Ma, J.; Dong, W.; Zhou, J.; Jiang, M.; Zhang, W.; Xin, F. The Draft Genome Sequence of Methylophilus sp. D22, Capable of Growing Under High Concentration of Methanol. Curr. Microbiol. 2019, 76, 1520-1524. [CrossRef]

8. Hirasawa, T.; Shimizu, H. Recent advances in amino acid production by microbial cells. Curr. Opin. Biotechnol. 2016, 42, 133-146. [CrossRef]

9. Abalakina, E.G.; Tokmakova, I.L.; Gorshkova, N.V.; Gak, E.R.; Akhverdyan, V.Z.; Mashko, S.V.; Yomantas, Y.A. Phage Mu-driven two-plasmid system for integration of recombinant DNA in the Methylophilus methylotrophus genome. Appl. Microbiol. Biotechnol. 2008, 81, 191-200. [CrossRef] [PubMed]

10. Doronina, N.V.; Gogleva, A.A.; Trotsenko, Y.A. Methylophilus glucosoxydans sp. nov., a restricted facultative methylotroph from rice rhizosphere. Int. J. Syst. Evol. Microbiol. 2012, 62, 196-201. [CrossRef] [PubMed]

11. Anthony, C.; Zatman, L.J. The microbial oxidation of methanol. 2. The methanol-oxidizing enzyme of Pseudomonas sp. M 27. Biochem. J. 1964, 92, 614-621. [CrossRef] [PubMed]

12. Chistoserdova, L.; Kalyuzhnaya, M.G. Current Trends in Methylotrophy. Trends Microbiol. 2018, 26, 703-714. [CrossRef] 
13. Saitou, N.; Nei, M. The neighbor-joining method: A new method for reconstructing phylogenetic trees. Mol. Biol. Evol. 1987, 4, 406-425. [CrossRef] [PubMed]

14. Kumar, S.; Stecher, G.; Li, M.; Knyaz, C.; Tamura, K. MEGA X: Molecular Evolutionary Genetics Analysis across Computing Platforms. Mol. Biol. Evol. 2018, 35, 1547-1549. [CrossRef] [PubMed]

15. Bankevich, A.; Nurk, S.; Antipov, D.; Gurevich, A.A.; Dvorkin, M.; Kulikov, A.S.; Lesin, V.M.; Nikolenko, S.I.; Pham, S.; Prjibelski, A.D.; et al. SPAdes: A new genome assembly algorithm and its applications to single-cell sequencing. J. Comput. Biol. 2012, 19, 455-477. [CrossRef]

16. Besemer, J.; Lomsadze, A.; Borodovsky, M. GeneMarkS: A self-training method for prediction of gene starts in microbial genomes. Implications for finding sequence motifs in regulatory regions. Nucleic Acids Res. 2001, 29, 2607-2618. [CrossRef]

17. Camacho, C.; Coulouris, G.; Avagyan, V.; Ma, N.; Papadopoulos, J.; Bealer, K.; Madden, T.L. BLAST+: Architecture and applications. BMC Bioinform. 2009, 10, 421. [CrossRef] [PubMed]

18. Parks, D.H.; Imelfort, M.; Skennerton, C.T.; Hugenholtz, P.; Tyson, G.W. CheckM: Assessing the quality of microbial genomes recovered from isolates, single cells, and metagenomes. Genome Res. 2015, 25, 1043-1055. [CrossRef] [PubMed]

19. Emms, D.M.; Kelly, S. OrthoFinder: Phylogenetic orthology inference for comparative genomics. Genome Biol. 2019, 20, 238. [CrossRef] [PubMed]

20. Buchfink, B.; Xie, C.; Huson, D.H. Fast and sensitive protein alignment using DIAMOND. Nat. Methods 2015, 12, 59-60. [CrossRef]

21. Edgar, R.C. MUSCLE: A multiple sequence alignment method with reduced time and space complexity. BMC Bioinform. 2004, 5, 113. [CrossRef] [PubMed]

22. Price, M.N.; Dehal, P.S.; Arkin, A.P. FastTree 2-approximately maximum-likelihood trees for large alignments. PLoS ONE 2010, 5, e9490. [CrossRef]

23. Goris, J.; Konstantinidis, K.T.; Klappenbach, J.A.; Coenye, T.; Vandamme, P.; Tiedje, J.M. DNA-DNA hybridization values and their relationship to whole-genome sequence similarities. Int. J. Syst. Evol. Microbiol. 2007, 57, 81-91. [CrossRef]

24. Jain, C.; Rodriguez, R.L.; Phillippy, A.M.; Konstantinidis, K.T.; Aluru, S. High throughput ANI analysis of 90K prokaryotic genomes reveals clear species boundaries. Nat. Commun. 2018, 9, 5114. [CrossRef] [PubMed]

25. Madhaiyan, M.; Poonguzhali, S.; Kwon, S.W.; Sa, T.M. Methylophilus rhizosphaerae sp nov., a restricted facultative methylotroph isolated from rice rhizosphere soil. Int. J. Syst. Evol. Microbiol. 2009, 59, 2904-2908. [CrossRef]

26. Jenkins, O.; Byrom, D.; Jones, D. Methylophilus-A New Genus of Methanol-Utilizing Bacteria. Int. J. Syst. Bacteriol. 1987, 37, 446-448. [CrossRef]

27. Tettelin, H.; Masignani, V.; Cieslewicz, M.J.; Donati, C.; Medini, D.; Ward, N.L.; Angiuoli, S.V.; Crabtree, J.; Jones, A.L.; Durkin, A.S.; et al. Genome analysis of multiple pathogenic isolates of Streptococcus agalactiae: Implications for the microbial "pan-genome". Proc. Natl. Acad. Sci. USA 2005, 102, 13950-13955. [CrossRef] [PubMed]

28. Dos Santos, J.P.; Iobbi-Nivol, C.; Couillault, C.; Giordano, G.; Mejean, V. Molecular analysis of the trimethylamine N-oxide (TMAO) reductase respiratory system from a Shewanella species. J. Mol. Biol. 1998, 284, 421-433. [CrossRef]

29. Lv, H.; Sahin, N.; Tani, A. Isolation and genomic characterization of Novimethylophilus kurashikiensis gen. nov. sp. nov., a new lanthanide-dependent methylotrophic species of Methylophilaceae. Environ. Microbiol. 2018, 20, 1204-1223. [CrossRef]

30. He, Y.; Feng, X.; Fang, J.; Zhang, Y.; Xiao, X. Metagenome and Metatranscriptome Revealed a Highly Active and Intensive Sulfur Cycle in an Oil-Immersed Hydrothermal Chimney in Guaymas Basin. Front. Microbiol. 2015, 6, 1236. [CrossRef]

31. Yang, Y.Y.; Wang, H.; Zheng, Y.; Zhu, B.L.; Wu, X.; Zhao, F. Extracellular electron transfer of Methylophilus methylotrophs. Process Biochem. 2020, 94, 313-318. [CrossRef]

32. Crundwell, F.K.; Holmes, P.R.; Fowler, T.A. How do bacteria interact with minerals? J. South. Afr. Inst. Min. Metall. 2000, 100, 399-401. [CrossRef]

33. Wu, Y.D.; Liu, T.X.; Li, X.M.; Li, F.B. Exogenous Electron Shuttle-Mediated Extracellular Electron Transfer of Shewanella putrefaciens 200: Electrochemical Parameters and Thermodynamics. Environ. Sci. Technol. 2014, 48, 9306-9314. [CrossRef]

34. van Staalduinen, L.M.; Jia, Z. Post-translational hydroxylation by $2 \mathrm{OG} / \mathrm{Fe}(\mathrm{II})$-dependent oxygenases as a novel regulatory mechanism in bacteria. Front. Microbiol. 2014, 5, 798. [CrossRef]

35. Loenarz, C.; Schofield, C.J. Physiological and biochemical aspects of hydroxylations and demethylations catalyzed by human 2-oxoglutarate oxygenases. Trends Biochem. Sci. 2011, 36, 7-18. [CrossRef]

36. Rollefson, J.B.; Stephen, C.S.; Tien, M.; Bond, D.R. Identification of an Extracellular Polysaccharide Network Essential for Cytochrome Anchoring and Biofilm Formation in Geobacter sulfurreducens. J. Bacteriol. 2011, 193, 1023-1033. [CrossRef] [PubMed]

37. Choi, S.; Kim, B.; Chang, I.S. Tracking of Shewanella oneidensis MR-1 biofilm formation of a microbial electrochemical system via differential pulse voltammetry. Bioresour. Technol. 2018, 254, 357-361. [CrossRef]

38. Jenal, U.; Reinders, A.; Lori, C. Cyclic di-GMP: Second messenger extraordinaire. Nat. Rev. Microbiol. 2017, 15, 271-284. [CrossRef] [PubMed]

39. Matsumoto, A.; Koga, R.; Kanaly, R.A.; Kouzuma, A.; Watanabe, K. Identification of a Diguanylate Cyclase That Facilitates Biofilm Formation on Electrodes by Shewanella oneidensis MR-1. Appl. Environ. Microbiol. 2021, 87, e00201-21. [CrossRef] [PubMed]

40. Kovacs-Simon, A.; Titball, R.W.; Michell, S.L. Lipoproteins of bacterial pathogens. Infect. Immun. 2011, 79, 548-561. [CrossRef] [PubMed] 
41. Roussel-Jazede, V.; Grijpstra, J.; van Dam, V.; Tommassen, J.; van Ulsen, P. Lipidation of the autotransporter NalP of Neisseria meningitidis is required for its function in the release of cell-surface-exposed proteins. Microbiology 2013, 159, 286-295. [CrossRef] [PubMed]

42. Coutte, L.; Willery, E.; Antoine, R.; Drobecq, H.; Locht, C.; Jacob-Dubuisson, F. Surface anchoring of bacterial subtilisin important for maturation function. Mol. Microbiol. 2003, 49, 529-539. [CrossRef] [PubMed]

43. Salcher, M.M.; Schaefle, D.; Kaspar, M.; Neuenschwander, S.M.; Ghai, R. Evolution in action: Habitat transition from sediment to the pelagial leads to genome streamlining in Methylophilaceae. ISME J. 2019, 13, 2764-2777. [CrossRef]

44. Kuypers, M.M.M.; Marchant, H.K.; Kartal, B. The microbial nitrogen-cycling network. Nat. Rev. Microbiol. 2018, 16, 263-276. [CrossRef] [PubMed]

45. Okubo, Y.; Skovran, E.; Guo, X.; Sivam, D.; Lidstrom, M.E. Implementation of microarrays for Methylobacterium extorquens AM1. OMICS 2007, 11, 325-340. [CrossRef] [PubMed] 